\title{
A fermented bean flour extract downregulates LOX-1, CHOP and ICAM-1 in HMEC-1 stimulated by ox-LDL
}

Morena Gabriele, Laura Pucci ${ }^{1 *}$, Margherita La Marca', Daniela Lucchesi ${ }^{3}$, Clara Maria Della Croce', Vincenzo Longo ${ }^{1}$ and Valter Lubrano ${ }^{2}$

\footnotetext{
*Correspondence: lauric16@yahoo.it ${ }^{1}$ National Research Council (CNR), Institute of Biology and Agricultural Biotechnology (IBBA), Pisa Unit, Research Area of Pisa, Via Moruzzi 1, 56124 Pisa, Italy

Full list of author information is available at the end of the article
}

\begin{abstract}
This study focused on an extract from fermented flour from the Lady Joy variety of the common bean Phaseolus vulgaris. The extract, Lady Joy lysate (Lys $L J)$, is enriched in antioxidant compounds during the fermentation. We assessed it for its protective effect on endothelial cells treated with oxidized-LDL (ox-LDL). The oxidative stress was determined by measuring the contents of thiobarbituric acid-reactive substances and reactive oxygen metabolites. ICAM-1, ET-1 and IL-6 concentrations were assessed using ELISA. LOX-1 and CHOP expression were analyzed using both quantitative RT-PCR and ELISA or western blotting. Ox-LDL treatment induced significant oxidative stress, which was strongly reduced by pre-treatment with the extract. The ox-LDL exposure significantly enhanced ICAM-1, IL-6 and ET-1 levels over basal levels. Lys $L J$ pre-treatment exerted an inhibitory effect on ox-LDL-induced endothelial activation with ICAM-1 levels comparable to those for the untreated cells. IL-6 and ET-1 production, although reduced, was still significantly higher than for the control. Both LOX-1 and CHOP expression were upregulated after ox-LDL exposure, but this effect was significantly decreased after $L y s ~ L J$ pre-treatment. Lys $L J$ alone did not alter the ICAM-1, IL-6 and ET-1 concentrations or CHOP expression, but it did significantly lower the LOX-1 protein level. Our data suggest that Lys $L J$ is an effective antioxidant that is able to inhibit the oxidation process, but that it is only marginally active against inflammation and ET-1 production in HMEC-1 exposed to ox-LDL.
\end{abstract}

Keywords: Fermented Phaseolus vulgaris L, HMEC-1, Oxidative stress, Ox-LDL, ER stress, CHOP, LOX-1, ICAM-1, IL-6, ET-1

Abbreviations: Apo B, apolipoprotein B; CHOP, C/EBP-homologous protein; ER, endoplasmic reticulum; EPCs, endothelial progenitors cells; ET-1, endothelin-1; EGF, epidermal growth factor; $F B S$, fetal bovine serum; $H D L$, high density lipoprotein; HMEC-1, human microvascular endothelial cells; HUVEC, human umbilical vein endothelial cells; IL-6, interleukin-6; ICAM-1, intracellular adhesion molecule; LOX-1, lectin-like oxidized low-density lipoprotein receptor-1; LJ, Lady Joy; LDL, low density lipoprotein; Lys LJ, Lady Joy lysate; MDA, malondialdehyde; M199, medium 199; NF-kB, nuclear factor-kB; Ox-LDL, oxidized-low density lipoprotein; ROS, reactive oxygen species; TBARs, thiobarbituric acid-reactive substances;

TNF-a, tumor necrosis factor alpha; UPR, unfolded protein response

\section{Biomed Central}

(c) 2016 The Author(s). Open Access This article is distributed under the terms of the Creative Commons Attribution 4.0 International License (http://creativecommons.org/licenses/by/4.0/), which permits unrestricted use, distribution, and reproduction in any medium, provided you give appropriate credit to the original author(s) and the source, provide a link to the Creative Commons license, and indicate if changes were made. The Creative Commons Public Domain Dedication waiver (http://creativecommons.org/ publicdomain/zero/1.0/) applies to the data made available in this article, unless otherwise stated. 


\section{Introduction}

Atherosclerosis is one of the major causes of cardiovascular disease. Szmitko et al. [1] describe it as a progressive and dynamic disease arising from inflammatory injury and endothelial dysfunction. Together with inflammatory mediators, endothelial dysfunction may contribute to different stages of atherosclerosis, including lesion formation and progression, plaque rupture, hemorrhage and thrombosis, and it is an early hallmark of the condition [2-4].

Vascular homeostasis is characterized by a tightly regulated action on vascular tone, cellular adhesion, vascular smooth muscle migration and resistance to thrombosis. It arises from a balance between vasodilators and vasoconstrictors, pro- and antioxidants, and pro- and anti-inflammatory molecules $[2,5]$.

Endothelial dysfunction occurs due to decreased nitric oxide bioavailability and an increased level of endothelin-1 (ET-1), angiotensin II and oxidants, which contribute to a disequilibrium in endothelium-derived relaxing and contracting factors [4]. Endothelial activation arises from an altered expression of cell surface adhesion molecules, such as intracellular adhesion molecule (ICAM-1); vascular cell adhesion molecule (VCAM) and E-selectin; pro-inflammatory cytokines such as tumor necrosis factor alpha (TNF- $\alpha$ ) and interleukin-6; and vasoactive mediators (prostaglandins, ET-1 and nitric oxide) [6]. ET-1 is one of the most potent vasoconstrictor peptides. It is synthesized and released mainly by the endothelial cells, and is also involved in the proliferation and hypertrophy of smooth muscle cells [7].

In the pathogenesis of atherosclerosis, oxidized low-density lipoproteins (ox-LDL) cause injury, activation and dysfunction of the endothelium via lectin-like oxidized low-density lipoprotein receptor-1 (LOX-1), which is overexpressed in both early and advanced atherosclerotic lesions [1]. Under conditions of hypertension, hypercholesterolemia and diabetes, all of which are pathological states characterized by chronic oxidative stress and high ox-LDL levels, LOX-1 is highly expressed in the blood vessels $[1,8]$. Identified as the major receptor for ox-LDL uptake in the endothelial cells, LOX-1 has also been found in macrophages, platelets, cardiac myocytes and vascular smooth muscle cells $[1,9,10]$. Through LOX-1 upregulation, ox-LDL induces increased levels of intracellular reactive oxygen species (ROS), which contribute to transcription-dependent adhesion molecule synthesis and expression via the activation of nuclear factor- $k B$ (NF-kB) $[1,11]$.

NF- $k B$ is an oxidant-sensitive transcription factor that plays a key role in the expression of pro-inflammatory genes, including interleukin-6 (IL-6) [12], a multifunctional cytokine that is widely implicated in cardiovascular disease. IL-6 secretion is upregulated in response to inflammation, angiotensin II and oxidative stress [4, 12].

Over the last decade, endoplasmic reticulum (ER) stress, often referred to as the unfolded protein response (UPR), has been recognized as a relevant factor in the promotion of atherosclerosis. Ox-LDL has emerged as an inducer of ER stress signaling in cultured endothelial cells through a mechanism involving altered ER calcium metabolism [13]. Ox-LDL also induces endothelial cell apoptosis via the LOX-1-dependent ER stress pathway and through the activation of ER stress sensors (IRE1 and PERK) and related pathways, which contribute to upregulation of the expression of DNA damage-inducible transcript 3 (CHOP), an ER stress-responsive transcription factor with pro-apoptotic activity [14]. 
Recent intervention trials assayed the effect of components of the Mediterranean diet on endothelial function [15]. Epidemiological evidence suggests the existence of a relationship between improved endothelial function and the consumption of foods containing polyphenols in both healthy people and patients with cardiovascular disease $[16,17]$. Noll et al. [18] also showed that daily intake of a red wine phenolic extract mainly composed of catechin and epicatechin had beneficial effects on plasma homocysteine levels and endothelial dysfunction biomarker expression in hyperhomocysteinemic mice. Furthermore, foodstuffs rich in procyanidin compounds, such as apple polyphenols and grape seed extracts, are reported to have an inhibitory effect on LOX-1 expression and ox-LDL binding to LOX-1 [19].

Common beans (Phaseolus vulgaris L.) are suggested to be nutraceutical due to their high content of bioactive compounds that improve endothelial function and exert anti-apoptotic, anti-aging, anti-tumor and anti-proliferative properties [20]. Cholesterol-lowering action and an inverse association between legume consumption and ischemic heart disease, coronary disease, type 2 diabetes and obesity have also been described [21, 22].

The recent increase in interest in fermented legumes as nutraceuticals with protective effects against cardiovascular diseases has led to an increase in their production and consumption [23]. Indeed, fermentation is now widely used to preserve and improve the texture, flavor and digestibility of several foods [24], including legumes, where it enhances the bioactive compound content and the antioxidant activity, decreasing non-nutritional factors [23].

As previously described by La Marca et al. [25], the fermentation of a flour derived from a genetically selected variety of $P$. vulgaris named Lady Joy yielded larger amounts of antioxidants, specifically polyphenols and flavonoids, compared to the unfermented flour. In this study, we investigated the effect of this fermented product (Lady Joy lysate) on the functional properties of human microvascular endothelial cells (HMEC-1) exposed to ox-LDL.

\section{Material and methods}

\section{Plant material}

The Lady Joy bean is a variety of Phaseolus vulgaris L. It is genetically devoid of the toxic constituent phytohemagglutinin and contains phaseolamin (an alpha-amylase inhibitor). Flour was produced by grinding the seeds, and the Lady Joy lysate (Lys LJ) was produced by fermenting and drying the flour. Lys LJ was extracted with distilled water, sonicated and centrifuged at $3500 \mathrm{rpm}$ in a Jouan CR3i centrifuge for $10 \mathrm{~min}$ at $4{ }^{\circ} \mathrm{C}$. The supernatant was collected, filtered $\left(0.2 \mu \mathrm{m}\right.$, VWR International PBI) and kept at $4{ }^{\circ} \mathrm{C}$ in the dark until use. The extraction was carried out in triplicate. The Lady Joy (LJ) flour and lysate compositions were detailed by La Marca et al. [25].

\section{LDL isolation and TBAR production}

LDL isolation and oxidation were performed as previously described [26]. The degree of oxidation was determined using a colorimetric method (Cayman Chemical) by measuring thiobarbituric acid-reactive substances (TBARs) expressed as nmol of malondialdehyde (MDA) per mg of LDL protein according to the method described by Esterbauer and Cheeseman [27]. 


\section{Cell culture}

The HMEC-1 line was obtained from the Centre for Disease Control. HMEC-1 cells retain morphological, phenotypic and functional characteristics of normal human microvascular endothelial cells. All of the media and medium supplements for cell culture were purchased from Sigma-Aldrich.

Cells were grown in 199 medium (M199) supplemented with $10 \%$ fetal bovine serum (FBS), $1 \%$ L-glutamine, 100 units $/ \mathrm{ml}$ penicillin, $100 \mu \mathrm{g} / \mathrm{ml}$ streptomycin, $10 \mathrm{ng} / \mathrm{ml}$ epidermal growth factor (EGF) and $1 \mu \mathrm{g} / \mathrm{ml}$ hydrocortisone at $37{ }^{\circ} \mathrm{C}$ in a humidified $5 \% \mathrm{CO}_{2}$ incubator.

In order to evaluate the effect of Lys LJ extract on cell viability, HMEC-1 cells were incubated for $24 \mathrm{~h}$ with increasing doses of Lys LJ extract, corresponding to 0, 0.07, 0.7 and $1.4 \mathrm{mg} / \mathrm{ml}$. The highest concentration devoid of toxic effects (i.e., with a cell viability of over $95 \%$ ) was used in further investigations.

Before each treatment, HMEC-1 were pre-incubated for $48 \mathrm{~h}$ with M199 without phenol red, containing antibiotics and $1 \%$ FBS. Then, after $1 \mathrm{~h}$ pre-treatment in the presence or absence of $0.7 \mathrm{mg} / \mathrm{ml}$ of Lys LJ extract, HMEC-1 were stimulated for $24 \mathrm{~h}$ with or without $200 \mu \mathrm{g}$ of apolipoprotein B (apo B) per ml of ox-LDL.

\section{Cell viability}

The trypan blue exclusion test and the MTT assay were performed to evaluate cell viability. The trypan blue exclusion test was used to count the number of viable cells presented in a cell suspension. Cells were trypsinized, harvested and then $10 \mu \mathrm{l}$ cell suspension was mixed with $10 \mu \mathrm{l} 0.4 \%$ trypan blue. Unstained (viable) and stained (nonviable) cells were counted separately in the hemacytometer.

The MTT assay measures mitochondrial activity in living cells. Briefly, cells were incubated with $100 \mu \mathrm{l} \mathrm{MTT} \mathrm{(Sigma;} 1 \mathrm{mg} / \mathrm{ml}$ ) for $2 \mathrm{~h}$ at $37{ }^{\circ} \mathrm{C}$ in $5 \% \mathrm{CO}_{2}$. Upon incubation, the medium was removed and the cells solubilized in $100 \mu \mathrm{l}$ of $10 \%$ DMSO/90 \% isopropanol. The amount of the dye released from the cells was quantified by measuring the optical density at $540 \mathrm{~nm}$ using an Eti-System multiplate reader (Sorin Biomedica). The optical density directly correlates with the amount of metabolically active cells.

\section{Reactive oxygen metabolite production}

Reactive oxygen metabolites (ROMs) were detected using a d-ROMs Kit (Diacron International) following the manufacturer's protocol. The results were expressed as a percentage relative to the control.

\section{Quantitative RT-PCR}

Total RNA was isolated from HMEC-1 using PureZOL RNA isolation reagent (Bio-Rad) and reverse-transcribed to cDNA using an iScript cDNA Synthesis Kit (Bio-Rad) following the manufacturer's protocol. Quantitative PCR was performed using the SsoFast EvaGreen Supermix (Bio-Rad) in the StepOnePlus Real-Time PCR System (Applied Biosystems). Gene primers were designed using Beacon Designer Software (Premier Biosoft International) and were: 
LOX-1 forward 5'-CCTTTGCCTGGGATTAGTAGT-3', reverse 5'-GCTCTTGTGTT AGGAGGTCA-3'

CHOP forward 5'-GAGAGTGTTCAAGAAGGAAGTGTA-3', reverse 5'-CCCGAAG GAGAAAGGCAAT-3'

$\beta$-actin forward 5'-GAGATGCGT-TGTTACAGGAAG-3', reverse 5'-TGGACTTGG GAGAGGACT-3'

$\beta$-actin was used as the housekeeping gene. Samples were assayed in triplicate and the gene expression was calculated using the $2^{-\Delta \Delta C T}$ relative quantification method.

\section{Immunoblot analysis}

Western blot analysis was performed according to La Marca et al. [25]. The antibodies used were anti-CHOP (1:500) and goat anti-rabbit (1:5000; Santa Cruz Biotechnology, Inc.). Immunoreactive proteins were visualized with a chemiluminescence reaction kit (EuroClone), and bands deriving from three independent experiments were electronically scanned and quantified with ImageJ software.

\section{ELISA}

The ICAM-1, ET-1 and IL- 6 concentrations in the medium were measured using an ELISA kit from Cayman Chemical. The LOX-1 protein level was evaluated via ELISA with a kit from Aviscera Bioscience.

\section{Statistical analyses}

Statistical analyses were performed using GraphPad Prism version 4.00 for Windows (GraphPad Software). Assays were carried out in triplicate and the results were expressed as the mean values $\pm \mathrm{SD}$. Differences between samples were analyzed via one-way analysis of variance (ANOVA) with Dunnett's multiple comparison test. A $p$ value lower than 0.05 is considered significantly different.

\section{Results}

As described by La Marca et al. [25], Lys LJ contained a significantly higher level of polyphenols ( $3.8 \pm 0.24$ vs. $2.348 \pm 0.05 \mathrm{mg} \mathrm{GAE} / \mathrm{g} \mathrm{DW}, p<0.001)$ and flavonoids $(2.1 \pm$ 0.1 vs. $1.6 \pm 0.1 \mathrm{mg} \mathrm{CE} / \mathrm{g} \mathrm{DW}, p<0.01)$ compared to the equivalent unfermented flour. It also showed a better antioxidant activity, as evaluated using the ORAC assay $(1233 \pm 23$ vs. $730 \pm 30 \mu \mathrm{mol} \mathrm{TE} / 100 \mathrm{~g} \mathrm{DW}, p<0.001)$. However, the flavonol concentration was reduced after fermentation $(0.4 \pm 0.1$ and $1.6 \pm 0.05 \mathrm{mg} \mathrm{QE} / \mathrm{g}$ dw respectively, $p<0.0001)$ and anthocyanins were not detected. Therefore, we tested the effect of the fermented bean flour on human microvascular endothelial cells (HMEC-1) under oxidative conditions.

To identify the optimal treatment conditions and detect possible cytotoxic effects, we used a toxicity curve with $0-1.4 \mathrm{mg} / \mathrm{ml}$ as the range of concentrations of Lys LJ extract. The highest concentration that did not cause toxic effects (i.e., cell viability of over $95 \%$ as determined using the Trypan Blue dye exclusion test and MTT assay) following $24 \mathrm{~h}$ exposure was used in further investigations (data not shown). As previously described by Lubrano et al. [28], we used $200 \mu \mathrm{g}$ of apo B/ml of ox-LDL to induce oxidative stress. We investigated the effect of $24 \mathrm{~h}$ exposure to $200 \mu \mathrm{g} / \mathrm{ml}$ ox-LDL, following $1 \mathrm{~h}$ pre-treatment with $0.7 \mathrm{mg} / \mathrm{ml}$ Lys LJ extract on HMEC-1 cells. 
The degree of oxidation following ox-LDL treatment was quantified as the formation of TBARs, which are lipid peroxidation markers. Their level was significantly higher in ox-LDL-exposed cells (10.9 nmole MDA/mg protein) than in untreated cells (1.76 nmole/ MDA/mg protein, ${ }^{* * * *} p<0.001$ vs. the control; Fig. 1a). Moreover, Lys LJ pre-treatment significantly reduced TBAR formation arising from ox-LDL exposure $(\& \& \& p<0.001)$ with values overlapping the control values (Fig. 1a). Otherwise, Lys LJ alone significantly decreased TBAR concentration compared to the values under basal conditions $(* * * * *$ 0.001; Fig. 1a).

Additionally, as shown in Fig. 1b, we detected a medium level of reactive oxygen metabolites (ROMs), which are free radical-derived compounds. Their levels were significantly increased by ox-LDL exposure $(* * p<0.001$ vs. the control). Although the level was reduced by Lys LJ pre-treatment ( \&\&p<0.01 vs. ox-LDL) it was still significantly higher than the control $\left({ }^{* *} p<0.01\right)$.

To identify the nutraceutical properties of Lys LJ, we tested its possible inhibitory effect on LOX-1 and CHOP expression and on the level of ICAM-1, IL-6 and ET-1 in the medium of endothelial cells following ox-LDL exposure. Quantitative PCR showed the expected significant upregulation of both LOX-1 $(* * * * 0<0.001$ vs. the control) and CHOP (** $p<0.001$ vs. the control) gene expression following ox-LDL treatment. This was strongly inhibited by Lys LJ pre-treatment $(\& \& \& p<0.001$ and $\& \& p<0.01$ vs. ox-LDL, respectively). Conversely, Lys LJ treatment alone had no effect (Figs. 2a and 3a). These results were also confirmed at the protein level as shown in Figs. $2 \mathrm{~b}$ and $3 \mathrm{~b}$. However, unlike with the gene expression, LOX-1 and CHOP proteins were reduced after Lys LJ pretreatment ( $\& \& \& p<0.001$ vs. ox-LDL) but were still higher than in the control cells $(* * * 00.001)$.

As shown in Fig. 4a-c, exposure of HMEC-1 to $200 \mu \mathrm{g} / \mathrm{ml}$ ox-LDL resulted in a significant upregulation of ICAM-1 $\left.{ }^{* *} p<0.01\right)$, IL-6 $(* * p<0.01)$ and ET-1 $\left({ }^{* * * *} p<0.001\right)$ concentrations in the medium compared to the untreated cells. Lys LJ pre-treatment exerted an inhibitory effect on ox-LDL endothelial activation with ICAM-1 levels overlapping the control values (Fig. 4a). Although Lys LJ pre-treatment of HMEC-1 cells exposed to ox-LDL reduced the levels of both IL-6 and ET-1, these levels
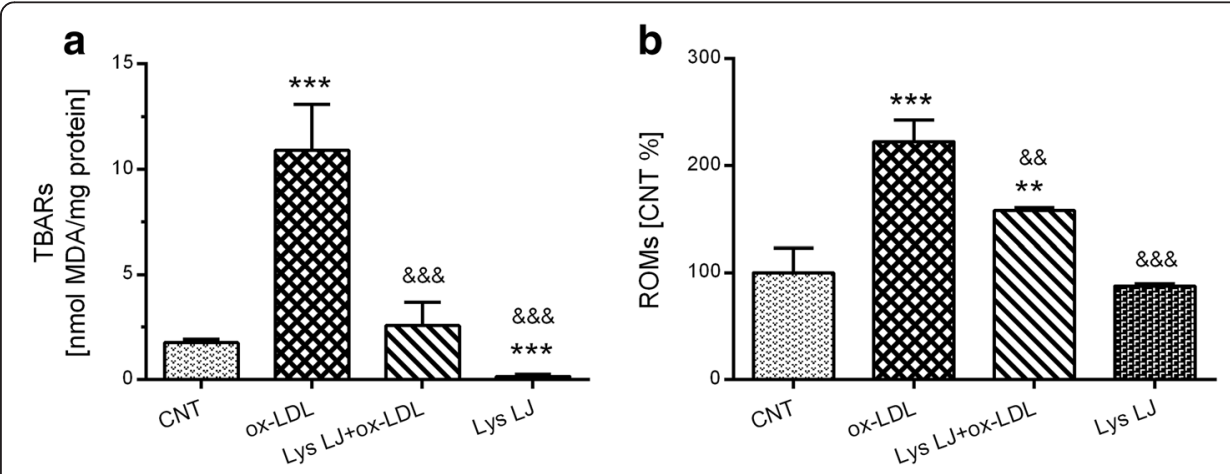

Fig. 1 Quantification of the levels of TBARs (a) and reactive oxygen metabolites (b) in HMEC-1 cells pre-treated for $1 \mathrm{~h}$ with or without $0.7 \mathrm{mg} / \mathrm{ml}$ Lys $\mathrm{LJ}$ extract, then exposed for $24 \mathrm{~h}$ to $200 \mathrm{\mu g}$ of apolipoprotein B (apo B) per $\mathrm{ml}$ of ox-LDL. Untreated cells were used as the control (CNT). Results are derived from triplicate determinations and expressed as means \pm SD. ANOVA with Dunnett's multiple comparison test. * Significantly

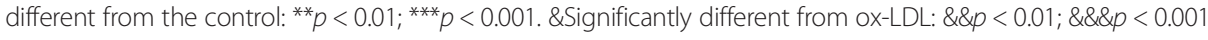



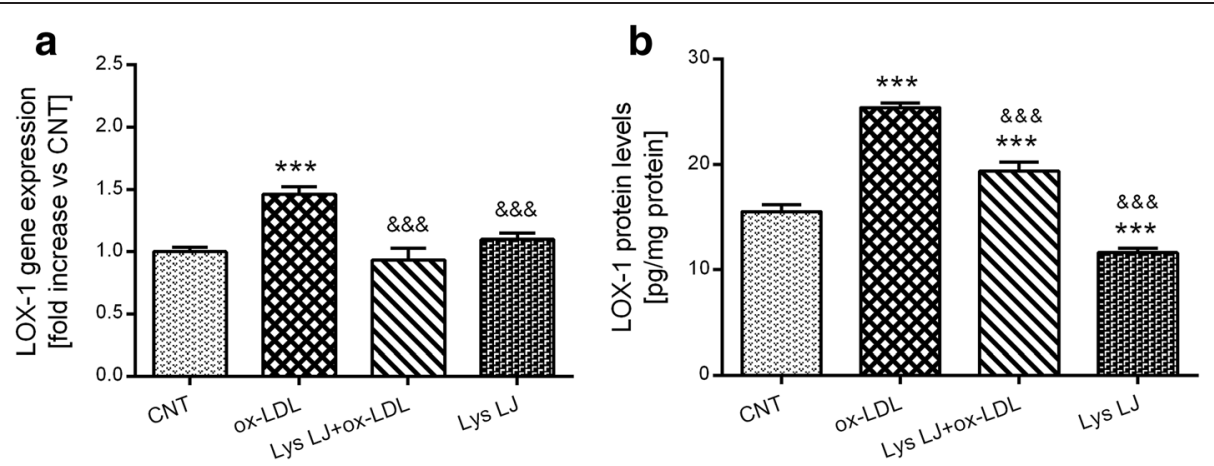

Fig. 2 Quantitative RT-PCR (a) and ELISA (b) determination of LOX-1 expression in HMEC-1 cells pre-treated for $1 \mathrm{~h}$ with $0.7 \mathrm{mg} / \mathrm{ml}$ Lys $\mathrm{LJ}$ extract, then exposed for $24 \mathrm{~h}$ to $200 \mu \mathrm{g}$ of apolipoprotein B (apo B) per $\mathrm{ml}$ of ox-LDL. Untreated cells were used as the control (CNT). Results are derived from triplicate determinations and expressed as means $\pm S D$. ANOVA with Dunnett's multiple comparison test. *Significantly different from the control: ${ }^{* *} p<0.001$. \&Significantly different from ox-LDL: \&\&\&p<0.001

remained significantly higher than in control cells (Fig. $4 \mathrm{~b}$ and c). The exposure of cells to Lys LJ treatment alone produced no significant change in IL-6 or ET-1 levels.

\section{Discussion}

Solid-state fermentation has recently been extensively used to improve the nutritional properties and enhance the bioactive compound content of certain foodstuffs, such as black beans [29]. As previously described by La Marca et al. [25], the fermentation process applied to Lady Joy bean flour increases the amount of antioxidants, in particular polyphenols and flavonoids, and significantly increases the antioxidant capacity of the bean lysate preparation compared to the unfermented flour. The same fermentation process applied to an organic grain flour named Lisosan $G$ showed similar results with beneficial effects on HMEC-1 following ox-LDL exposure [30].

We previously showed improved human endothelial progenitor cell functions after Lys LJ pre-treatment in terms of cell viability, adhesion capacity and senescence rate both
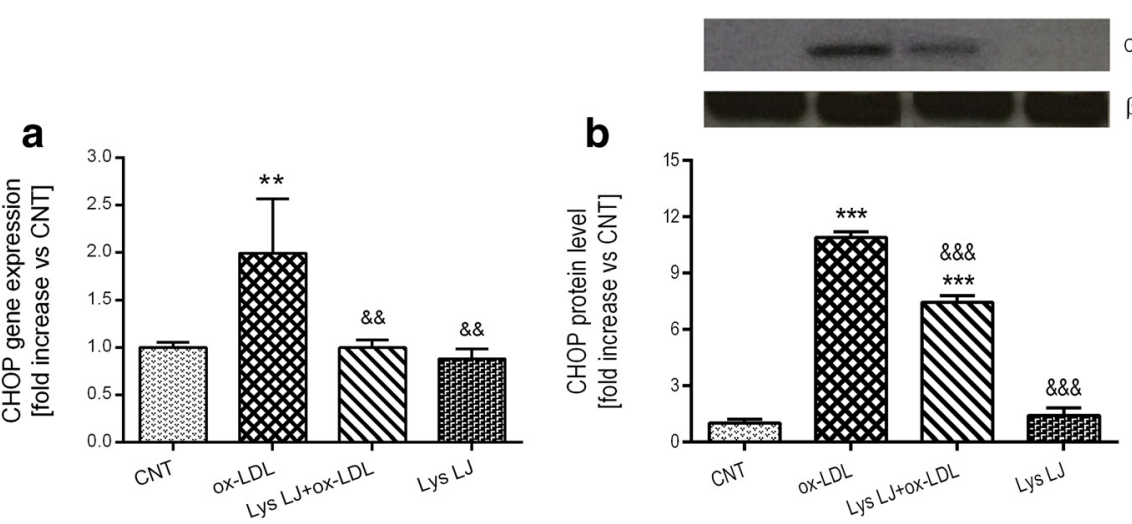

Fig. 3 Quantitative RT-PCR (a) and western blot (b) analysis of CHOP expression in HMEC-1 pre-treated for $1 \mathrm{~h}$ with $0.7 \mathrm{mg} / \mathrm{ml}$ Lys $\sqcup$ extract, then exposed for $24 \mathrm{~h}$ to $200 \mathrm{\mu g}$ of apolipoprotein B (apo B) per ml of ox-LDL. Untreated cells were used as the control (CNT). The results are derived from triplicate determinations and expressed as means $\pm S D$. ANOVA with Dunnett's multiple comparison test. *Significantly different from the

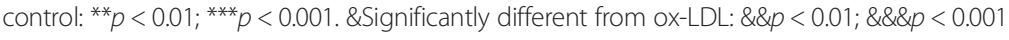



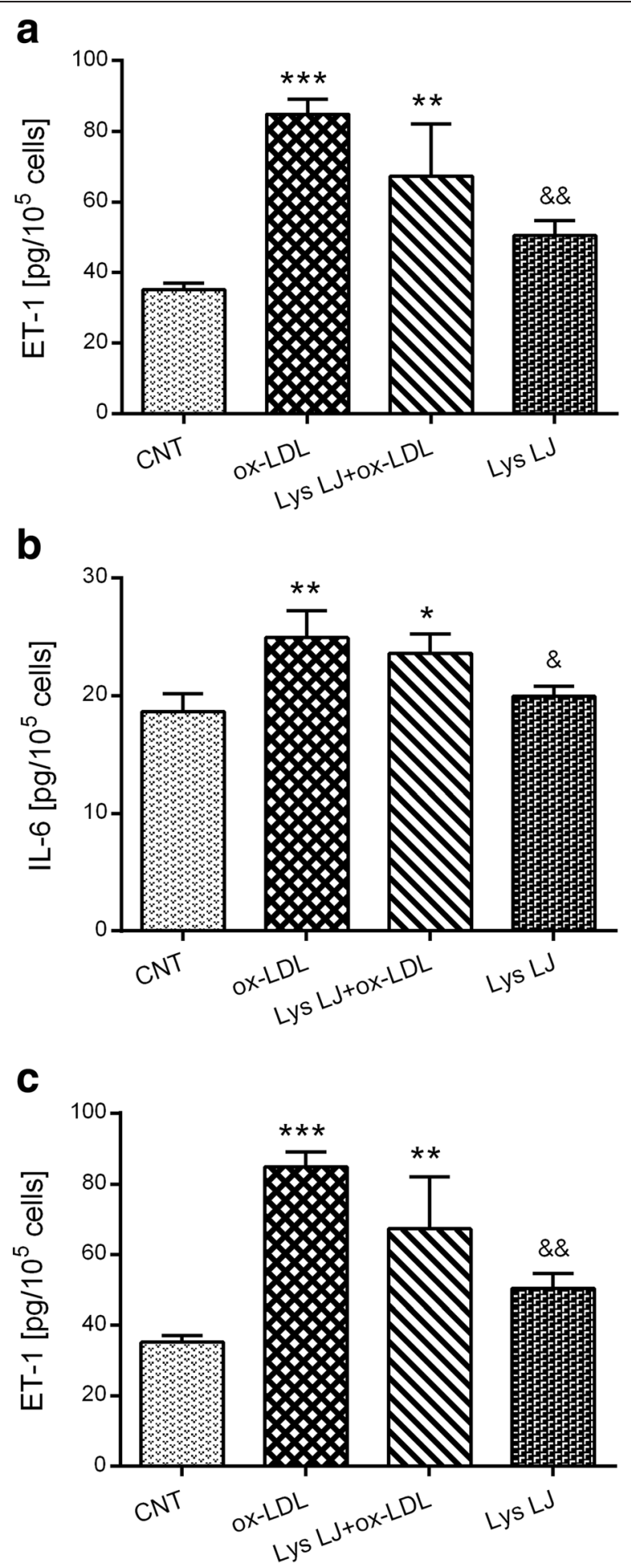

Fig. 4 ELISA determination of ICAM-1 (a), IL-6 (b) and ET-1 (c) production in the medium of HMEC-1 cells pre-treated for $1 \mathrm{~h}$ with $0.7 \mathrm{mg} / \mathrm{ml}$ Lys $\sqcup$ extract, then exposed for $24 \mathrm{~h}$ to $200 \mu \mathrm{g}$ of apolipoprotein B (apo B) per ml of ox-LDL. Untreated cells were used as the control (CNT). Results are derived from triplicate determinations and expressed as means \pm SD. ANOVA with Dunnett's multiple comparison test. * Significantly different from the control: ${ }^{*} p<0.05 ;{ }^{* *} p<0.01 ;{ }^{* * *} p<0.001$. \&Significantly different from ox-LDL: \&p<0.05; $\& \& p<0.01 ; \& \& \& p<0.001$ 
under basal conditions and following $\mathrm{H}_{2} \mathrm{O}_{2}$ exposure [31]. Furthermore, we investigated the effect of Lys LJ on human erythrocytes exposed to a radical generator, showing a good cellular antioxidant activity and a higher hemolysis inhibition following Lys LJ pre-treatment. We also described good anti-mutagenic and antioxidant activity following oxidative injury in the Saccharomyces cerevisiae D7 strain pre-treated with Lys LJ extract [32].

To better define the nutraceutical properties of Lys LJ, we investigated the effect of pre-treatment with the extract in human microvascular endothelial cells. Overall, our findings show that Lys LJ pre-treatment could improve endothelial function otherwise impaired by ox-LDL exposure. In particular, Lys LJ pre-treatment could counteract the oxidation process arising from ox-LDL treatment and reduce the endothelial endogenous stress.

Thus, Lys LJ pre-treatment reduced the expression of LOX-1 at both the mRNA and protein levels. They were otherwise upregulated by exposure to lipoperoxides or free radical agents, which influences endothelial disfunction by promoting the generation of superoxide anions, the inhibition of nitric oxide production and the enhanced adhesion of monocytes to the endothelium [33, 34]. LOX-1 also contributes to inflammation and smooth muscle cell proliferation, leading to atheroma formation at multiple levels $[35,36]$. The beneficial effects of Lys LJ were observed in these microvascular endothelial cells as the reduction of CHOP expression at both the mRNA and protein levels, in keeping with the earlier observations of La Marca et al. [25] with primary rat hepatocyte cultures exposed to $\mathrm{H}_{2} \mathrm{O}_{2}$.

The inhibitory effects of Lys LJ pre-treatment on the induction of ICAM-1 by ox-LDL treatment is noteworthy, where this pre-treatment completely inhibits the induction of ICAM-1 into the medium of HMEC-1 cells following ox-LDL treatment. These results are in keeping with a recent study in which flavonoids exhibited a good anti-inflammatory effect and reduced ICAM-1 expression in human aortic endothelial cells [37]. A similar effect was detected for HMEC-1 exposed to ox-LDL following pre-treatment with Lisosan $G$ [38], which contains a significant amount of polyphenols [31]. Lys LJ pre-treatment was less effective with IL-6 and ET-1, where the increase in medium levels following ox-LDL treatmen was only partially reduced.

A recent study showed a synergic action of olive oil and wine polyphenols in the modulation of ox-LDL effects on oxidative stress [39]. Moreover, it has been demonstrated that the polyphenol fraction of extra virgin olive oil protected endothelial cells from free fatty acid-induced dysfunction by reversing ET-1 impairment [40]. Another recent paper showed that, among polyphenols, only resveratrol and quercetin were effective in decreasing $\mathrm{H}_{2} \mathrm{O}_{2}$-induced ET-1 overexpression in a dose-dependent manner in human umbilical vein endothelial cells (HUVEC). Although those authors did not provide a clear explanation for this, they suggested that these effects could depend upon the chemical structure and/or the antioxidant activity. Others reported that these two polyphenols showed the highest antioxidant capacities as measured by the ferric reducing antioxidant power assay [41].

We can therefore assume that this fermented bean flour may reduce oxidative stress by decreasing both lipoperoxides and free radicals. Our data also show an important role of Lys LJ in reducing endothelial adhesiveness, one of the main events in endothelial activation and plaque formation [42]. Indeed, adhesion of monocytes to the 
endothelium is one of the earliest cellular events in atherogenesis. Several mechanisms compete to recruit and promote cell-cell interaction between monocytes and endothelial cells [43].

\section{Conclusions}

This study demonstrated the beneficial effects of a fermented bean flour lysate on human microvascular endothelial cells exposed to oxidative injury. Our results suggest that Lys LJ (Lady Joy lysate) is a strong antioxidant able to reduce the degree of oxidation, ER stress and endothelial adhesiveness induced by ox-LDL treatment. However, it is poorly active against inflammation and ET-1 induction resulting from pro-oxidant injury in human microvascular endothelial cells. The fermentation process applied to the bean flour is a useful procedure to enrich and ameliorate the nutritional properties of this legume, which might prove to be a useful nutraceutical for preventing cardiovascular diseases.

\section{Acknowledgements}

The authors would like to thank R. Bollini and F. Sparvoli (CNR, IBBA, Milano, Italy) for providing the Lady Joy bean and the Agrisan Company (Larciano, Italy) for providing the Lady Joy bean lysate. The authors are also grateful to Dr. Lucrecia Mota Garcia for her support with the manuscript.

\section{Availability of data and materials}

Data and materials listed in the paper are available in our laboratories.

\section{Authors' contributions}

Conceived and designed the experiments: MG LP VLu. Performed the experiments: MG, MLM, CMDC, VLu. Analyzed the data: MG, LP, VLu. Contributed reagents/materials/analysis tools: DL, VLo. Contributed to the writing of the manuscript: $M G, L P, V L u$. Read and approved the final draft and submission of the manuscript: $M G, L P, M L M, D L$, CMDC, VLO, VLU.

Competing interests

The authors declare that they have no competing interest.

\section{Author details}

${ }^{1}$ National Research Council (CNR), Institute of Biology and Agricultural Biotechnology (IBBA), Pisa Unit, Research Area of Pisa, Via Moruzzi 1, 56124 Pisa, Italy. Fondazione CNR/Regione Toscana G. Monasterio, Via Moruzzi 1, 56124 Pisa, Italy. ${ }^{3}$ Department of Clinical and Experimental Medicine, Section of Metabolic Diseases, University of Pisa, Via Paradisa 2, 56124 Pisa, Italy.

Received: 30 October 2015 Accepted: 9 February 2016

Published online: 12 August 2016

\section{References}

1. Szmitko PE, Wang CH, Weisel RD, Jeffries GA, Anderson TJ, Verma S. Biomarkers of vascular disease linking inflammation to endothelial activation: Part II. Circulation. 2003;108:2041-8.

2. Steyers 3rd CM, Miller Jr FJ. Endothelial dysfunction in chronic inflammatory diseases. Int J Mol Sci. 2014;15:11324-49.

3. Bonetti PO, Lerman LO, Lerman A. Endothelial dysfunction-a marker of atherosclerotic risk. Arterioscler Thromb Vasc Biol. 2003;23:168-75.

4. Szmitko PE, Wang CH, Weisel RD, de Almeida JR, Anderson TJ, Verma S. New markers of inflammation and endothelial cell activation: Part I. Circulation. 2003;108:1917-23.

5. Donato AJ, Pierce GL, Lesniewski LA, Seals DR. Role of NFkappaB in age-related vascular endothelial dysfunction in humans. Aging. 2009;1:678-80.

6. Chan EL, Murphy JT. Reactive oxygen species mediate endotoxin-induced human dermal endothelial NF-kappaB activation. J Surg Res. 2003;111:120-6.

7. Félétou M, Vanhoutte PM. Endothelial dysfunction: a multifaceted disorder (The Wiggers Award Lecture). Am J Physiol Heart Circ Physiol. 2006;291:H985-1002.

8. Mango R, Predazzi IM, Romeo F, Novelli G. LOX-1/LOXIN: the yin/yang of atheroscleorosis. Cardiovasc Drugs Ther. 2011:25:489-94.

9. Iwai-Kanai E, Hasegawa K, Sawamura T, Iwai-Kanai E, Hasegawa K, Sawamura T. Activation of lectin-like oxidized low-density lipoprotein receptor-1 induces apoptosis in cultured neonatal rat cardiac myocytes. Circulation. 2001;104:2948-54.

10. Lubrano V, Balzan S. LOX-1 a new marker of risk and prognosis in coronary artery disease? Mol Cell Biochem. 2013;383:223-30

11. Granger DN, Senchenkova E. Inflammation and the Microcirculation. In: Granger DN, Granger JP, editors. Colloquium Series in Integrated Systems Physiology: from Molecules to Function. Princeton: Morgan \& Claypool Life Sciences; 2010 
12. Taniyama Y, Griendling KK. Reactive oxygen species in the vasculature: molecular and cellular mechanisms. Hypertension. 2003;42:1075-81.

13. Tabas I. The role of endoplasmic reticulum stress in the progression of atherosclerosis. Circ Res. 2010;107:839-50.

14. Hong D, Bai YP, Gao HC, Wang X, Li LF, Zhang GG, Hu CP. Ox-LDL induces endothelial cell apoptosis via the LOX-1-dependent endoplasmic reticulum stress pathway. Atherosclerosis. 2014;235:310-7.

15. Storniolo CE, Casillas R, Bulló M, Castañer O, Ros E, Sáez GT, Toledo E, Estruch R, Ruiz-Gutiérrez V, Fitó M, Martínez-González MA, Salas-Salvadó J, Mitjavila MT, Moreno JJ. A Mediterranean diet supplemented with extra virgin olive oil or nuts improves endothelial markers involved in blood pressure control in hypertensive women. Eur J Nutr. 2015. doi:10.1007/s00394-015-1060-5.

16. Grassi D, Lippi C, Necozione S, Desideri G, Ferri C. Short-term administration of dark chocolate is followed by a significant increase in insulin sensitivity and a decrease in blood pressure in healthy persons. Am J Clin Nutr. 2005;81:611-4.

17. Schmitt CA, Dirsch VM. Modulation of endothelial nitric oxide by plant-derived products. Nitric Oxide. 2009;21:77-91.

18. Noll C, Lameth J, Paul JL, Janel N. Effect of catechin/epicatechin dietary intake on endothelial dysfunction biomarkers and proinflammatory cytokines in aorta of hyperhomocysteinemic mice. Eur J Clin Nutr. 2013;52:1243-50.

19. Nishizuka T, Fujita Y, Sato Y, Nakano A, Kakino A, Ohshima S, Kanda T, Yoshimoto R, Sawamura T. Procyanidins are potent inhibitors of LOX-1: a new player in the French Paradox. Proc Jpn Acad Ser B Phys Biol Sci. 2011;87:104-13.

20. Reynoso-Camacho R, Ramos-Gomez M, Loarca-Pina G. Bioactive compounds in common bean (Phaseolus vulgaris L.). In: Guevara-González RG, Torres-Pacheco I, editors. Advances in Agricultural and Food Biotechnology. Signpost: Kerala; 2006. p. 217-36.

21. Anderson JW, Major AW. Pulses and lipaemia, short- and long-term effect: potential in the prevention of cardiovascular disease. Br J Nutr. 2002;88:S263-71.

22. Kalogeropulos N, Chiou A, loannou M, Kothanos VT, Hanapidou M, Androkopulos NK. Nutritional evaluation and bioactive microconstituents (phytosterols, tocopherols, polyphenols, triterpenic acids) in cooked dry legumes usually consumed in the Mediterranean countries. Food Chem. 2010;121:682-90.

23. Limón Rl, Peñas E, Torino Ml, Martínez-Villaluenga C, Dueñas M, Frias J. Fermentation enhances the content of bioactive compounds in kidney bean extracts. Food Chem. 2015;172:343-52.

24. Ali NM, Yeap SK, Yusof HM, Beh BK, Ho WY, Koh SP, Abdullah MP, Alitheen NB, Long K. Comparison of free amino acids, antioxidants, soluble phenolic acids, cytotoxicity and immunomodulation of fermented mung bean and soybean. J Sci Food Agric. 2015. doi:10.1002/jsfa.7267.

25. La Marca M, Pucci L, Bollini R, Russo R, Sparvoli F, Gabriele M, Longo V. Antioxidant effect of a fermented powder of Lady Joy bean in primary rat hepatocytes. Cell Mol Biol Lett. 2015;20:102-16.

26. Lubrano V, Gabriele M, Puntoni MR, Longo V, Pucci L. Relationship among IL-6, LDL cholesterol and lipid peroxidation. Cell Mol Biol Lett. 2015;20:310-22.

27. Esterbauer $\mathrm{H}$, Cheeseman K. Determination of aldehyde lipid peroxidation products: malonaldehyde and 4-hydroxinonenal. Methods Enzymol. 1990;186:407-21.

28. Lubrano V, Vassalle C, Blandizzi C, Del Tacca M, Palombo C, L'Abbate A, Baldi S, Natali A. The effect of lipoproteins on endothelial nitric oxide synthase is modulated by lipoperoxides. Eur J Clin Invest. 2003;33:117-25.

29. Martins S, Mussatto SI, Martínez-Avila G, Montañez-Saenz J, Aguilar CN, Teixeira JA. Bioactive phenolic compounds: production and extraction by solid-state fermentation. A review. Biotechnol Adv. 2011;29:365-73.

30. La Marca M, Beffy P, Pugliese A, Longo V. Fermented wheat powder induces the antioxidant and detoxifying system in primary rat hepatocytes. PLoS One. 2013;8, e83538.

31. Lucchesi D, Russo R, Gabriele M, Longo V, Del Prato S, Penno G, Pucci L. Grain and bean lysates improve function of endothelial progenitor cells from human peripheral blood: involvement of the endogenous antioxidant defenses. PLoS One. 2014;9, e109298.

32. Frassinetti S, Gabriele M, Caltavuturo L, Longo V, Pucci L. Antimutagenic and antioxidant activity of a selected lectin-free common bean (Phaseolus vulgaris L.) in two cell-based models. Plant Foods Hum Nutr. 2015;70:35-41.

33. Cominacini L, Rigoni A, Pasini AF, Garbin U, Davoli A, Campagnola M, Pastorino AM, Lo Cascio V, Sawamura T. The binding of oxidized low density lipoprotein (ox-LDL) to ox-LDL receptor-1 reduces the intracellular concentration of nitric oxide in endothelial cells through an increased production of superoxide. J Biol Chem. 2001;276:13750-5.

34. Mehta JL, Li DY, Chen HJl, Joseph J, Romeo F. Inhibition of LOX-1 by statins may relate to upregulation of eNOS. Biochem Biophys Res Commun. 2001;289:857-61.

35. Inoue N, Sawamura T. Lectin-like oxidized LDL receptor-1 as extracellular chaperone receptor: its versatile functions and human diseases. Methods. 2007;43:218-22.

36. Lawson C, Wolf S. ICAM-1 signaling in endothelial cells. Pharmacol Rep. 2009;61:22-32.

37. Freischmidt A, Jürgenliemk G, Kraus B, Okpanyi SN, Müller J, Kelber O, Weiser D, Heilmann J. Contribution of flavonoids and catechol to the reduction of ICAM-1 expression in endothelial cells by a standardised Willow bark extract. Phytomedicine. 2012;19:245-52.

38. Lubrano V, Baldi S, Napoli D, Longo V. Beneficial effect of Lisosan G on cultured human microvascular endothelial cells exposed to oxidised low density lipoprotein. Indian J Med Res. 2012;136:82-8.

39. Vivancos M, Moreno JJ. Effect of resveratrol, tyrosol and beta-sitosterol on oxidised low-density lipoprotein-stimulated oxidative stress, arachidonic acid release and prostaglandin E2 synthesis by RAW 264.7 macrophages. Br J Nutr. 2008;99:1199-207.

40. Storniolo CE, Roselló-Catafau J, Pintó X, Mitjavila MT, Moreno JJ. Polyphenol fraction of extra virgin olive oil protects against endothelial dysfunction induced by high glucose and free fatty acids through modulation of nitric oxide and endothelin-1. Redox Biol. 2014;2C:971-7.

41. Nicholson SK, Tucker GA, Brameld JM. Physiological concentrations of dietary polyphenols regulate vascular endothelial cell expression of genes important in cardiovascular health. Br J Nutr. 2010;103:1398-403.

42. Bao M, Lou Y. Flavonoids from seabuckthorn protect endothelial cells (EA.hy926) from oxidized low-density lipoprotein induced injuries via regulation of LOX-1 and eNOS expression. J Cardiovasc Pharmacol. 2006;48:834-41.

43. Rao RM, Yang L, Garcia-Cardena G, Luscinskas FW. Endothelial-dependent mechanisms of leukocyte recruitment to the vascular wall. Circ Res. 2007;101:234-47. 